\title{
Complexity of Social Interactions in Collaborative Learning: The Case of Online Database Environment
}

\author{
Rikki Rimor, Yigal Rosen, and Kefaya Naser \\ Department of Education and Psychology, \\ The Open University of Israel, Raanana, Israel
}

\section{rikkiri@openu.ac.il; igal.rosen@gmail.com; nkefaya@gmail.com}

\begin{abstract}
This study examines and classifies patterns of interaction in a collaborative database learning environment (Google Docs) by analyzing interactions between 44 graduate students in an Open University course. The patterns of interaction were examined according to a model that tested the degree of collaboration in an online learning environment (Weinberg \& Fischer, 2006). The purpose of the study was to examine how the participants reach consensus in the process of database construction. Advanced computer technologies constitute a useful communicative environment for collaborative learning and provide platforms that support interactive learning characterized by collaboration. They facilitate mutual supervision of content studied, development of real-time learning strategies, debate, and cultivation of thinking skills. This gives rise to the following questions: How are the various parameters of interaction expressed in an online database learning environment? What patterns of group interaction develop and how do they do so in this collaborative online environment? The findings of the study present a number of different patterns that develop in this kind of environment and show that the patterns of interaction that emerged did in fact reveal different levels of complexity. It seems that the collaborative environment of the online database contributes to the development of complex patterns of interaction while performing tasks.
\end{abstract}

Keywords: Collaborative learning, social interactions, thinking skills, online database.

\section{Introduction}

Computer technologies enable intellectual partnership between the individual learner and advanced intelligent tools. These technologies are mainly intended for activities and intellectual partnerships that encourage thinking and learning in a social context (Rosen \& Salomon, 2007;

Material published as part of this publication, either on-line or in print, is copyrighted by the Informing Science Institute. Permission to make digital or paper copy of part or all of these works for personal or classroom use is granted without fee provided that the copies are not made or distributed for profit or commercial advantage AND that copies 1) bear this notice in full and 2) give the full citation on the first page. It is permissible to abstract these works so long as credit is given. To copy in all other cases or to republish or to post on a server or to redistribute to lists requires specific permission and payment of a fee. Contact Publisher@InformingScience.org to request redistribution permission.
Salomon, 2000). The theoretical basis for learning as a social process was developed by Vygotsky (1978) who placed great emphasis on the social context of the learning process. This perception became particularly relevant in relation to learning processes involving communications-based computer technologies. Vygotsky stressed the importance of the interaction between the learner and his/her environment, including the im-

\section{Editor: Alex Koohang}

An earlier, shorter version of this paper was presented at the Chais conference 2010, in Raanana, Israel, and included in Y. Eshet-Alkalai, A. Caspi, S. Eden, N. Geri, \& Y. Yair (Eds.), Proceedings of the Chais conference on instructional technologies research 2010: Learning in the technological era. Raanana: The Open University of Israel. http://www.openu.ac.il/research center eng/conferences.html 
portance of support and feedback during the learning process, and he introduced the gap between the level of performance and the level of the learner's personal potential as the Zone of Proximal Development. He claimed that the personal potential could be realized through a process of interaction with and support from the human environment and from various tools. Thus, under optimal conditions, reciprocal interpersonal activity could lead to intrapersonal mental development, in other words, the connection between social functioning and cognitive functioning. When trying to solve a problem together through the exchange of ideas, a team of learners constructs shared meanings that the individual would not have attained alone. The collaborative parameter and the social context of a meaningful learning process are expressed through raising issues for group discussion based on prior knowledge and joint confrontation of the problems, the outcome of which is the ongoing development of thinking. In light of this perception, researchers claim that, on the one hand, one may refer to interpersonal communications that are internalized by the individual and serve personal-cognitive functions, and, on the other, one may refer to joint meaning appropriation. Intelligence is not a matter of (individual) ownership, but a quality that grows out of interpersonal negotiation.

\section{Theoretical Background}

The use of information technology (IT) for learning enables collaborative learning and has become a popular topic of research within the field of education. Sharing may take place at different stages of the learning, such as knowledge sources, data collection, information processing, information outcomes, and outcome assessment (Hathorn \& Ingram, 2002). An effective task is one that enables all participants to express themselves and make significant contributions to the final product.

It appears that technology tools, following the development of advanced IT communications, are a platform that promotes and encourages collaborative learning and, thus, might help close the gap between the level of performance and the learner's level of personal potential within the collaborative and interactive learning process. Researchers claim that computer-mediated communications is an excellent medium for activities involving debate, reflection, and better learning (Williams, Duray, \& Venkateshwar, 2006). The use of IT affects the collaborative interaction between students and enhances learning (Alavi \& Gallupe, 2003). Web-based communications, especially in the Web 2.0 era, contribute to the advancement of collaborative learning since they encourage pro-activism among users to create social ties, share human experiences, and generate new knowledge for rapid distribution and cooperation (Herwing, Mathias, Strohmaier, Dosinger, $\&$ Tochtermann, 2007). The interaction between the participants in an online environment also creates an important sense of belonging (Rovai, 2002).

It seems that there is a close correlation between learning as a social process and the perception of learning as the construction of knowledge. In computer-based learning, the emphasis shifts to interactive learning through cooperation and collaboration among all participants in the process. In the online environment, text has greater significance than in the traditional classroom, since the text typed online exists simultaneously with and contributes to the collaboration between the members of the group. This is a significant extension of the learning and discussion framework as well as of the social context and enrichment of the knowledge construction process that benefits all those involved (Herwing et al., 2007; Little et al., 2009; Stahl, Koschmann, \& Suthers, 2006; Weinberger \& Fischer, 2006). Alongside its many advantages, it appears that collaborative learning also raises difficulties in the interaction among participants. The application of learning and teaching technologies demands a certain degree of technical literacy, which, in turn, might require further investment in the acquisition of the necessary technical skills (Frank, Reich, \& Humphreys, 2003; Yan, 2006). Moreover, some researchers claim that personal traits that are essential for collaborative learning, such as a sense of belonging and mutual trust, are lacking in the transi- 
tion to virtual space (Caspi \& Blow, 2008; Frank et. al., 2003; Kreijns, Kirschner, \& Jochems, 2003). Distance learning also often requires self-discipline (Winters, Greene, \& Costich, 2008). In order to succeed in online group work, participants need to invest in developing shared norms and work procedures. Peer pressure may not be optimal for collaboration and might not allow for original independent thought. The need to fit in with the group's learning pace or level of discussion might sometimes adversely affect personal aspirations and achievements. Similarly, because of the complexity of tasks in this environment, the odds of increased cognitive load causing problems of understanding among the participants might lead to conflict and drive participants to seek easier shortcuts (Kreijns et al., 2003; Puntambekar, 2006). The difficulty in collaborating and reaching a consensus might, thus, constitute a source of problems and difficulties. On the other hand, researchers claim that more emphasis must be placed on the challenge of these experiences alongside the aspiration to reach shared understanding and that the very participation in the learning process, with all the problems inherent in reaching a consensus about the results, is highly important for the promotion of learning in social contexts (Chen \& Chiu, 2008).

In order to examine the patterns of social interaction that take place in an online collaborative environment, the different aspects of the process must be conceptualized. Weinberger and Fischer (2006) propose four parameters of collaborative learning to construct knowledge in an online environment: (1) participation (2) epistemology (cognitive) (3) discussion (4) social collaboration in the co-construction of knowledge. Our research focuses on the fourth parameter which relates to the social activity within knowledge construction through group discussion, with five levels of collaboration:

a. Externalization - Discussion usually begins with externalization, when the learner contributes to the discussion without referring to the contributions of the other learners. People externalize their knowledge in order to explain their point of view. Following the externalization, the group embarks on a social process of knowledge construction.

b. Initiative - Group members reciprocally serve as sources of knowledge by asking questions and by obtaining knowledge from their learning partners (Dillenbourg, Baker, Blaye, \& O'Malley, 1995). Research findings have shown that in successful learning groups, more questions are asked and participants display greater creativity in problem solving and metacognitive thinking than less successful groups (King, 1999; Rimor, 2002; Rosenshine, Meister, \& Chapman, 1996). On the other hand, there is concern that the learners will become so dependent on the help of their group members that they will not be able to function independently and originally (Webb, Ender, \& Lewis, 1986).

c. Rapid consensus - In order to generate collaboration among group members, the learners accept the opinions of their peers, not necessarily because they agree with them or have been persuaded, but because it is a way to quickly advance with the discussion. This does not allow for measurement of the consensus among group members or any change in their attitudes, but there is an indication of activity matching (Fischer, Bruhn, Grsel, \& Mandl, 2002; Weinberger, 2003). In this way, the learners must negotiate to a general consensus regarding the learning tasks. There are a number of ways to reach a consensus but rapid consensus is the most efficient (Clark \& Brennan, 1991). Its limitation lies in the fact that it detracts from personal knowledge, and a sense of disrespect for some members of the group might arise (Nastasi \& Clements, 1992).

d. Integrative consensus - The learners reach a consensus through an integration of their various opinions and points of view. They create a synthesis of their ideas in order to understand the task logically (Nastasi \& Clements, 1992). Unlike the construction of rapid consensus, which is assisted by a kind of 'takeover' by one particular opinion, integration occurs when individual learners analyze the conclusions drawn by their peers and are ready to change their own opinions or accept those of their peers until a consensus is reached. 
It seems that integration usually occurs usually at the end of the process, when the group members concur or change their opinions (Keefer, Zeitz, \& Resnick, 2000; Weinberger, 2003).

e. Consensus through conflict - When building a consensus, the learners must either present their objections clearly and persuasively or present an alternative. In a case of conflict learners are open to criticism, thus there is a good chance that they will find better arguments to support and justify their opinions since they are open to criticism in a state of conflict. Creating a consensus through conflict is an important element in the social-cognitive process in collaborative learning (Chen \& Chiu, 2008; Doise \& Mugny, 1984; Teasley, 1997). Moreover, the difference between parameters $\mathbf{d}$ and $\mathbf{e}$ lies in the length of discussions among participants. When constructing an "integrative consensus" the discussion is shorter because there is no conflict among participants regarding the task. In a "consensus through conflict," relatively more time is needed for discussion and persuasion.

In this study, we use the above five parameters to analyze qualitatively the patterns of social interactions in an online collaborative database environment.

\section{Research Questions}

The following questions were empirically examined in this study:

1. To what extent does an online collaborative database environment promote the following types of social interactions: externalization, initiation, rapid consensus, integrative consensus, consensus through conflict?

2. What patterns of social interactions (string of social interaction measures) develop in an online collaborative database environment?

\section{Method}

Forty-four graduate students participated in an online course that referred to knowledge construction processes in technologically-based environments. The students were required to take part in an online collaborative assignment based on constructing a shared database on the Internet. The purpose of the assignment was to construct a database representing various types of knowledge, based on items from the forum of the course. The construction of the database included students' selection of statements from the course forum and classifying them according to four types of knowledge: declarative, procedural, structural, meta-cognitive. The work was carried out online in a collaborative "Google Docs" database (Google Spreadsheets). The construction of a Google database enables cognitive activities of organizing, classifying, and representing data in a collaborative environment (Rosen \& Rimor, 2009). The learning activities were conducted in teams of 34 students (free choice), over the course of six weeks. The process of database construction was initiated by each student classifying three selected statements in the forum and re-locating them in the proper fields of the database relating to the various types of knowledge: declarative, procedural, structural, and meta-cognitive. This activity was accompanied by individual argumentation as well as social interaction among the participants. At the end of the process, the students made a final team decision regarding the classification of the statements. All the classifications and explanations were documented in the database. The participants shared a common purpose, a prior knowledge of the types of knowledge, a common virtual space for classifying their statements, and a common space for presenting arguments, reasoning, and questions during the process of the database construction. The purpose was to reach collaborative agreement in the team in regard to sorting the forum's statements in the database.

Overall there were 238 items in the collaborated database. In the first phase of the study, we classified qualitatively these items according to the Weinberger and Fischer (2006) model which ana- 
lyzes argumentative knowledge construction in computer-supported collaborative learning. This model examines the degree of collaboration in an online learning environment using five dimensions: externalization, initiation, rapid consensus, integrative consensus, consensus through conflict. Frequency of each dimension was calculated based on 238 single items.

The second phase of the study focused on qualitative characterization of social interactions. We identified strings of dimensions that were represented in the database by the protocols of the discussions for each team of students. Identifying different strings allowed us to classify various types of social interactions. For example the following string was classified as "ExternalizationInitiative-Rapid consensus":

Group member \#1: I think that it is a procedural knowledge. The sentence refers to the description of web search procedure.

Group member \#2: Yes you're right.

Group member \#3: I agree with you. We can use the reference from our third lesson to prove that it is a procedural knowledge.

The final phase of the study referred to the qualitative examination of the complexity of the social interactions and their frequency. The most complex interaction was composed of the dimensions of "integrative consensus" and "consensus through conflict," whereas the least complex interaction was represented by the dimension of externalization.

\section{Results}

Table 1 presents the frequency of social interaction dimensions as found in the discussions developed in the online collaborative database environment. The findings indicate that learning activity in this environment strongly promotes "rapid consensus" (29\%) and "initiative" (25\%). Learners accept the opinions of their peers, not necessarily because they agree with them or have been persuaded, but because it is a way to advance quickly with the discussion. By asking questions and obtaining knowledge from their partners (initiative) they mutually serve as sources of knowledge. In addition, we found that learning in an online collaborative database environment encourages externalization (20\%), where learners contribute to the discussion without referring to the contributions of other learners, and "integrative consensus" (16\%) where the learners create a synthesis of their ideas in order to understand the task logically. In addition, relatively low frequency was found in the context of "consensus through conflict" as learners present their objections clearly and persuasively or present an alternative perspective (10\%).

Table 1: Frequency of social interaction dimensions in online collaborative database environment

\begin{tabular}{c|c|c}
\hline Relative Frequency (\%) & Frequency & Dimension of Social Interaction \\
\hline 20 & 49 & 1. Externalization \\
\hline 25 & 59 & 2. Initiative \\
\hline 29 & 68 & 3. Rapid consensus \\
\hline 16 & 39 & $4 . \quad$ Integrative consensus \\
\hline 10 & 23 & $5 . \quad$ Consensus through conflict \\
\hline
\end{tabular}


Table 2 presents patterns of social interaction found in this study in the discussion protocol of each team. A pattern was created by identifying different types of social interaction dimensions strings of items - as was represented in the collaborated database.

Table 2: Frequency of social interaction patterns in online collaborative database environment

\begin{tabular}{c|c|l}
\hline Relative Frequency (\%) & Frequency & Social Interaction Pattern \\
\hline 3 & 3 & 1. Externalization \\
\hline 15 & 14 & 2. Externalization-Initiative \\
\hline 3 & 3 & $3 . \quad \begin{array}{l}\text { Externalization-Initiative- } \\
\text { Rapid consensus }\end{array}$ \\
\hline 21 & 20 & $\begin{array}{l}\text { 4. } \\
\text { Externalization-Rapid con- } \\
\text { sensus }\end{array}$ \\
\hline 5 & 5 & $\begin{array}{l}\text { Externalization-Rapid con- } \\
\text { sensus- Initiation }\end{array}$ \\
\hline 23 & 6 & $\begin{array}{l}\text { Initiative- Externalization- } \\
\text { Initiative- Rapid consensus }\end{array}$ \\
\hline 24 & 22 & $\begin{array}{l}\text { Externalization-Rapid con- } \\
\text { sensus- Integrative consen- } \\
\text { sus }\end{array}$ \\
\hline & 23 & $\begin{array}{l}\text { Externalization-Initiative- } \\
\text { Rapid consensus- Integra- } \\
\text { tive consensus- Consensus } \\
\text { through conflict }\end{array}$ \\
\hline
\end{tabular}

Patterns 1-6 can be defined as relatively simple social interactions, due to the fact that the more complex dimensions ("integrative consensus" and "consensus through conflict") are not presented in these patterns. Externalization-Rapid consensus (21\%) and Externalization-Initiative (15\%) were found as the most frequent low level (simple) interactions.

More complex patterns, as found in this study, can be characterized by multiplicity and variety of dimensions (at least three dimensions). Two main patterns were found in this category: Externalization-Rapid consensus- Integrative consensus (23\%), and Externalization-Initiative- Rapid consensus-Integrative consensus-Consensus through conflict (24\%).

In addition, we found that $75 \%$ of the social interaction patterns included "rapid consensus." In more simple patterns, the groups' members agree upon the solution in initial stages of the activity without being involved in a deep argumentative process. On the other hand, more complex social interactions start with partial consensus, and therefore the teams' members need to go through an argumentative collaborative process including integration or changing perspectives (integrative consensus or consensus through conflict).

\section{Discussion and Conclusions}

The current research aimed at examining and analyzing the social interactions which were created through the process of collaborative construction of knowledge in an online learning environment (Google Docs). We used qualitative and quantitative measures to analyze participants' input in 
the database. Content analysis of students' assertions was performed using Weinberger and Fischer (2006) dimensions of online collaborative interaction. The frequency of each dimension was calculated in order to estimate to what extent the online collaborative database environment promotes various types and patterns of social interaction. Two levels of analysis were used. The first level referred to single criteria of interaction, one dimension to represent each interaction, whereas on the second level we identified patterns of dimensions which classify several successive interactions. The first research question focused on the various parameters of interaction expressed in the online Google Docs collaborative database.

The findings of this study show that the interaction among learners in a Google Docs collaborative database is composed of various dimensions of interaction and that most of these dimensions represent a relatively low level of complexity. This includes dimensions such as: "externalization" - when the learner contributes to the discussion without referring to the contributions of other learners; "initiative" - when group members reciprocally serve as sources of knowledge by asking questions and by obtaining knowledge; and "rapid consensus" - when learners accept the opinions of their peers not necessarily because they agree with them or have been persuaded, but rather because it is a way to quickly advance with the discussion.

Our findings show that at the single criteria level, externalization assertions along with initiation assertions constitute nearly half of all assertions. Due to the fact that the frequency of externalization assertions are slightly lower than those of initiation assertions, it would appear that participants tend to initiate investigations regarding perspectives and attitudes of others at a relatively higher frequency than merely externalizing their own personal knowledge. Moreover, the dimension of externalization is an essential component for the start of any discussion and can be considered a default first stage of any discussion in the database environment. In other words: after externalization there is a tendency to cooperate with others by requesting a response to a question or statement (initiation).

The tendency to receive feedback and ask questions is considered to be one of the fundamental characteristics for a successful study group, showing creativity in problem solving and metacognitive thinking (King, 1999; Rimor, 2002; Rosenshine, et. al 1996).

Findings show that the most frequent dimension at the single criteria level is one of rapid agreement building, in other words, accepting the contribution of group members in order to advance in a common task (Weinberger \& Fischer, 2006). More complex interactions, including building an integrative agreement and building a conflict agreement, come close to the scale of rapid agreement occurrence, with a negligible difference of $26 \%$ versus $29 \%$ respectively. It seems that, along with the acceptance of contributions from group members and coordinating activity among participants, we can also identify integration of group members' perspectives as well as changes of perspectives and perceptions during conflicts evolving among the participants. Hence, in terms of consensus building, we identified heterogeneous interaction dimensions.

The study's second question focused on identifying patterns of group interaction as they evolved in an online learning environment while constructing a collaborative database. In order to provide an answer to this question, all discussions were classified into eight patterns of interaction consisting of different levels of complexity. These patterns were analyzed using frequency analysis. The results show that the most common pattern of interaction was the most complex pattern, which incorporated all five dimensions of interaction: externalization, initiation, rapid agreement building, building integrative agreements, and building an agreement amidst a conflict. Discussions adhering to this pattern constitute a quarter of all discussions. Additional interaction patterns with a slightly lower rate, compared to more complex patterns of interaction are: externalization-rapid agreement and integrative agreement building and a pattern consisting of externalization and rapid agreement which do not evolve into more complex levels of discussion. 
Our findings show that the frequency of complex interactive patterns of discussions that evolved into integrative and conflict agreements consists of close to $50 \%$ of all discussions developing amongst students in the collaborative database environment. In such cases, cooperation between students can be summed up as a synthesis of ideas developed via integration, different opinions and viewpoints and, in many cases, via constructive criticism that encourages the development of alternatives and contributes to enriching the process (Chen \& Chiu, 2008; Doise \& Mugny, 1984; Fisher et al., 2002; Keefer et al., 2000; Teasley, 1997; Weinberger, 2003). On the other hand, the findings show that just over $50 \%$ of the discussions did not develop nor did they reach complex agreement stages and, at best, reached the stage of rapid agreement which indicates no change in participants' perceptions.

In our study, the most frequent interactive characteristic amongst students studying via a collaborative, online database is the most complex characteristic that combines all five aspects of interaction ended by the building of an agreement through conflict among the various perspectives. The participants reached their common goal gradually from externalizing their own personal knowledge to examining others' points of view, creating a synthesis between different opinions as well as critically negotiating among themselves to reach an integration of points of view or to change their own perspectives. We claim that the process of constructing an online collaborative database allowed the development of knowledge construction through various patterns of interactions. These interactions are characterized by mutual contribution and integration of perspectives as well as critical and mutual negotiations and argumentation.

Evidently, the discussion was extended due to the existence of a conflict regarding the subject of the discussion that demanded the suggestion of alternatives. As a result, great efforts were made at persuasion. Frequency findings for relatively complex interactions confirm the claim regarding the potential of advanced computer technology for interactive learning that is characterized by building knowledge cooperation through discussion (Alavi \& Gallupe, 2003; Davie \& Wells, 1991; Herwing et al., 2007; Salomon, 2000; Williams et al., 2006). This refers to learning as a decentralized social process of knowledge creation through social interaction that involves all participants in a democratic fashion. The difficulty of gaining consensus in the midst of conflict between perceptions and opinions can also contribute to learning and knowledge building cooperation through discussion and the nurturing of thought processes (Chen \& Chiu, 2008; Little et al., 2009; Stahl et al., 2006). Findings show that half of the discussions among participants did not develop into relatively complex levels of interaction. Often, discussions ended at the stage of externalization of personal knowledge, with no contribution being made from other participants. Often, the discussion developed from the stage of externalization to one of initiation, in order to clarify the opinions and viewpoints of other participants, and ceased at this level. In other words, the use of advanced communications technology for the purpose of collaborative learning does not, by itself, guarantee the development of complex interactions. In fact, the opposite is true. The results show empirical support to the claim that, in many cases, the need for cooperation does not benefit the participants and does not allow for independent, original thinking due to the social stress applied by the group (Kreijns et al., 2003; Puntambekar, 2006). Clear examples of this are discussions that end in rapid agreement. In such cases, rapid agreement cannot be seen as a stage that allows for the continuation of the discussion but rather the result of the domination of one specific viewpoint that negatively impacts the personal knowledge of the other participants and that can lead to feelings of disparagement amongst some of the group members (Nastasi \& Clements, 1992). On occasion, the need to adhere to the group's learning rate or to the group's level of discussion can harm aspirations and cause some participants to refrain from stating views or expressing opinions. In this situation relatively strong or assertive students may gain an advantage over others. This may diminish the value of equality which is one of the foundations of cooperative learning and collaboration work targeted towards a democratic group effort and based 
on the idea of mutual contributions (Alavi \& Gallupe, 2003; Kirschner, Martens, \& Strijbos, 2004; Oliver \& Herrington, 2003; Rovai, 2002).

Further research is recommended to examine the development of patterns of social interaction in different contexts of various courses, task demands, technological literacy of participants, as well as the teacher's feedback and support.

\section{References}

Alavi, M., \& Gallupe, R. (2003). Using information technology in learning: Case studies in business and management education programs. Academy of Management Learning and Education, 2, 139-153.

Caspi, A., \& Blau, I. (2008). Social presence in online discussion groups: Testing three conceptions and their relations to perceived learning. Soc Psychol Educ, 11, 323-346.

Chen, G., \& Chiu, M. (2008). Online discussion processes: Effects of earlier messages' evaluations, knowledge content, social cues and personal information on later messages. Computers \& Education, 50(3), 678-692.

Clark, H. H., \& Brennan, S. E. (1991). Grounding in communication. In L. Resnick, J. Levine, \& S. Teasley (Eds.), Perspectives on socially shared cognition. Washington, DC: American Psychological Association.

Davie, L., \& Wells, R. (1991). Empowering the learner through computer-mediated communication. The American Journal of Distance Education, 5, 15-23.

Dillenbourg, P., Baker, M., Blaye, A., \& O’Malley, C. (1995). The evolution of research on collaborative learning. In P. Reimann \& H. Spada (Eds.), Learning in humans and machines: Towards an interdisciplinary learning science. Oxford: Elsevier.

Doise, W., \& Mugny, G. (1984). The social development of the intellect. Oxford: Pergamon.

Fischer, F., Bruhn, J., Grsel, C., \& Mandl, H. (2002). Fostering collaborative knowledge construction with visualization tools. Learning and Instruction, 12, 213-232.

Frank, M., Reich, N., \& Humphreys, K. (2003). Respecting the human needs of students in the development of e-learning. Computers \& Education, 40(1), 57-70.

Hathorn, L. G., \& Ingram, A. L. (2002). Online collaboration: Making it work. Educational Technology. $42(1), 33-40$.

Herwing, R., Mathias, L., Strohmaier, M., Dosinger, G., \& Tochtermann, K. (2007). The Web 2.0 way of learning with technologies. International Journal of Learning Technology, 3(1), 87-107.

Keefer, M., Zeitz, C., \& Resnick, L. (2000). Judging the quality of peer-led student dialogues. Cognition and Instruction, 18(1), 53-81.

King, A. (1999). Discourse patterns for mediating peer learning. In A. O’Donnell \& A. King (Eds.), Cognitive perspectives on peer learning. Mahwah, NJ: Erlbaum.

Kirschner, P., Martens, R., \& Strijbos, J. (2004). CSCL in higer education? A framework for designing multiple-collaborative environments. In J. Strijbos, P. Krischner, \& R. Martens (Eds.), What we know about CSCL and implementing it in higher education. Boston: Kluwer Academic Publishers .

Kreijns, C., Kirschner, P., \& Jochems, W. (2003). Identifying the pitfalls for social interaction in computersupported collaborative learning environments: A review of the research. Computers in Human Behavior, 19(3), 335-353.

Little, J., Page, C., Betts, K., Bonne, S., Faverty, P., Joosten, T., et al. (2009). Charting the Course and Tapping the Community: The EDUCAUSE Top Teaching and Learning Challenges 2009. EDUCAUSE Review, 44(3), 30-45. 
Nastasi, B. K., \& Clements, D. H. (1992). Social-cognitive behaviors and higher-order thinking in educational computer environments. Learning and Instruction, 2, 215-238.

Oliver, R., \& Herrington, J. (2003). Exploring technology-mediated learning from a pedagogical perspective. Interactive Learning Environments, 11(2), 111-126.

Puntambekar, S. (2006). Analyzing collaborative interactions: Divergence, shared understanding and construction of knowledge. Computers \& Education, 47(3), 332-351.

Rimor, R. (2002). From search for information to construction of knowledge: Organization and construction of knowledge in database environment. Unpublished doctoral dissertation. Ben-Gurion University of the Negev, Israel (in Hebrew).

Rosen, Y., \& Rimor, R. (2009). Using collaborative database to enhance students' knowledge construction. Interdisciplinary Journal of E-Learning and Learning Objects, 5, 187-195. Retrieved from http://www.ijello.org/Volume5/IJELLOv5p187-195Rosen671.pdf

Rosen, Y. \& Salomon, G. (2007). The differential learning achievements of constructivist technologyintensive learning environments as compared with traditional ones: A Meta-Analysis. Journal of Educational Computing Research, 36(1), 1-14.

Rosenshine, B., Meister, C., \& Chapman, S. (1996). Teaching students to generate questions: A review of the intervention studies. Review of Educational Research, 66(2), 181-221.

Rovai, A. P. (2002). Building sense of community at a distance. International Review of Research in Open and Distance Learning, 3(1), 1-16.

Salomon, G. (2000). Technology and education in the age of information. Haifa, Israel: Haifa University Press. (In Hebrew).

Stahl, G., Koschmann, T., \& Suthers, D. (2006). Computer-supported collaborative learning: An historical perspective. In R. K. Sawyer (Ed.), Cambridge handbook of the learning sciences (pp. 409-426). Cambridge, UK: Cambridge University Press.

Teasley, S. (1997). Talking about reasoning: How important is the peer in peer collaboration? In L. B. Resnick, R. Saljo, C. Pontecorvo, \& B. Burge (Eds.), Discourse, tools and reasoning: Essays on situated cognition. Berlin: Springer.

Vygotsky, L. (1978). Mind and society: The development of higher mental processes. Cambridge, MA: Harvard University Press.

Webb, N. M., Ender, P., \& Lewis, S. (1986). Problem-solving strategies and group processes in small groups learning computer programming, American Educational Research Journal, 23(2), 243-261.

Weinberger, A. (2003). Scripts for computer-supported collaborative learning: Effects of social and epistemic cooperation scripts on collaborative knowledge construction. Unpublished doctoral dissertation. Ludwig-Maximilian University, Munich, Germany. Available from: http://edoc.ub.unimuenchen.de/archive/00001120/01/Weinberger_Armin.pdf.

Weinberger, A., \& Fischer, F. (2006). A framework to analyze argumentative knowledge construction in computer-supported collaborative learning. Computers \& Education, 46, 71-95.

Williams, E., Duray, R., \& Venkateshwar, R. (2006). Teamwork orientation, group cohesiveness, and student learning: A study of the use of teams in online distance education. Journal of Management Education, 30, $592-616$.

Winters, F., Greene, J., \& Costich, C. (2008). Self-regulation of learning within computer-based learning environments. Educational Psychology Review, 20(4), 429-444.

Yan, Z. (2006). Different experiences, different effects: a longitudinal study of learning a computer program in a network environment. Computers in Human Behavior, 22(3), 364-380. 


\section{Biographies}

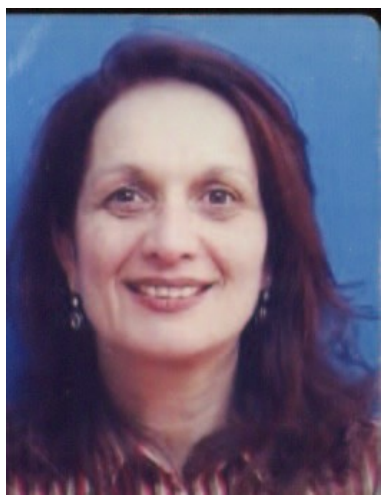

Rikki Rimor is currently a faculty member and course designer in the Dept. of Education and Psychology, Graduate program of Learning Technologies, and serves as Academic Consultant to the university's Unit for advancement of learning and teaching. Earlier she was Head of Center for Pedagogy \& Innovative Technologies, Teachers' College of Technology, Tel-Aviv. Her PhD thesis "From Search for Information to Construction of Knowledge" is from Ben-Gurion University of the Negev, Department of Education. Her most recent publication include: Rimor, R. \& Rosen, Y. (2010). Collaborative Knowledge Construction in Online Learning Environment: Why to Promote and How to Investigate. In: Cases on Technological Adaptability and Transnational Learning: Issues and Challenges. IGI-Global, USA.

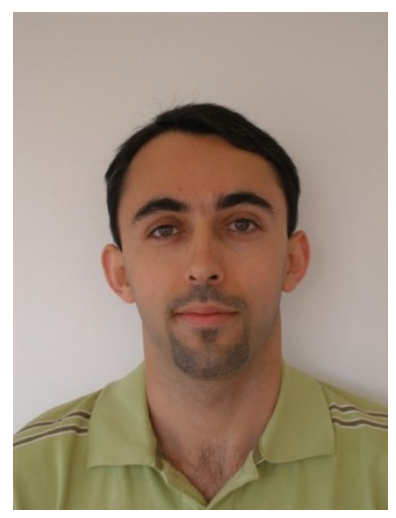

Dr. Yigal Rosen's research interests focus on developing higher-order thinking skills in technology-rich learning environments, assessment and educational evaluation. He obtained his $\mathrm{PhD}$ degree from the Faculty of Education at the University of Haifa in 2006. Dr. Rosen was a post-doctoral fellow at School of Education at Tel Aviv University (2006-2007) and a post-doctoral fellow at the Graduate School of Education at Harvard University (2007-2008). He is a faculty member at The Open University of Israel, Department of Education and Psychology and at the University of Haifa, Faculty of Education. Dr. Rosen is a head of assessment and evaluation in educational technology company Time To Know.

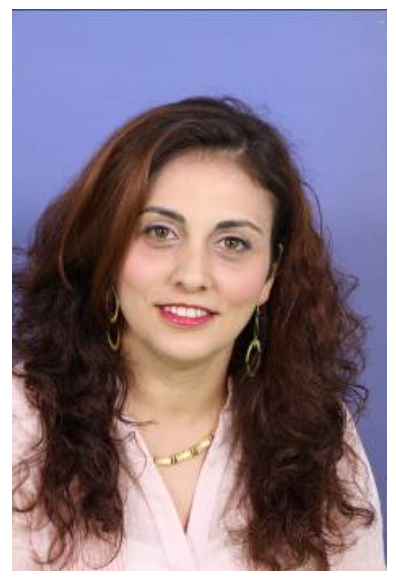

Kefaya Naser is a graduate student at The Open University of Israel, Department of Education and Psychology with specialization of learning technologies. Her research interests focus on social interactions in online learning. She is a mathematics teacher and a professional development instructor. 